\title{
The joint subclinical elevation of CRP and IL-6 is associated with lower health-related quality of life in comparison with no elevation or elevation of only one of the biomarkers
}

\author{
Peter Garvin $^{1,2} \cdot$ Evalill Nilsson $^{1,2} \cdot$ Jan Ernerudh $^{3} \cdot$ Margareta Kristenson $^{2}$
}

Accepted: 8 July 2015/Published online: 21 July 2015

(c) The Author(s) 2015. This article is published with open access at Springerlink.com

\begin{abstract}
Background Measures of health-related quality of life (HRQoL), like the Short Form (SF)-36, have been suggested to correlate with inflammatory biomarkers. It is, however, unclear whether a joint measure of two inflammatory biomarkers would bring additional information in comparison with evaluation of one inflammatory biomarker.

Objective To evaluate associations between SF-36 and low-grade inflammation in a Swedish population, with emphasis on a combined measure of C-reactive protein (CRP) and interleukin-6 (IL-6) as a proxy for low-grade inflammation.

Methods In a randomly selected sample of a middle-aged Swedish general population ( $n=905$; aged 45-69 years, $50 \%$ women), relations between SF-36 parameters and the biomarkers were tested. Regression and correlation analyses were adjusted for sex, age, presence of disease, lifestyle, and psychological factors.

Results After adjustment for sex and age, HRQoL was significantly lower in the group with a joint elevation of CRP and IL-6 in comparison with either the group with no elevation or the groups showing elevation of one of the two
\end{abstract}

Peter Garvin

peter.garvin@regionostergotland.se

1 Unit of Research and Development in Local Health Care (FoU-enheten för Närsjukvården i Östegötland), County of Östergötland, 58185 Linköping, Sweden

2 Division of Community Medicine, Department of Medical and Health Sciences, Linköping University, Linköping, Sweden

3 Division of Neuro and Inflammatory Sciences, Department of Clinical and Experimental Medicine, Linköping University, Linköping, Sweden biomarkers. Also after full adjustments, the combined measure of elevated CRP and IL-6, with few exceptions, was associated with significantly lower HRQoL in comparison with elevations in one of them, difference ranging from 4 (Mental Health scale) to 18 scale steps (RolePhysical scale).

Conclusion This study confirms that there is a relationship between HRQoL and low-grade inflammation. In particular, SF-36 scores are significantly lower in a group with joint elevation of IL-6 and CRP, in comparison with elevation of either one of them.

Keywords Biomarkers - CRP - Health-related quality of life $\cdot$ Inflammation $\cdot$ Interleukin $\cdot$ Population $\cdot$ SF-36

\section{Introduction}

Measures of health-related quality of life (HRQoL) are increasingly used as patient-reported outcome measures (PROM) within the health-care system, and the assessment constitutes a potentially important tool for health-care improvement. Profound understanding of the relations of HRQoL to other (health-related) factors is therefore crucial for the interpretation of HRQoL data. HRQoL measures can be either generic, measuring general health problems, or disease-specific, i.e., measuring health issues of importance for a certain disease or condition. One of the most commonly used generic measures is the Medical Outcome Study Short Form-36 (SF-36) questionnaire [1], a multiitem measure which includes 36 questions in eight different health dimensions (scales), covering physical, social, and mental function and well-being.

Several groups have independently shown that low SF36 scores are associated with increased mortality risk 
[2-4]. We have previously shown that each of the scales of the SF-36, in addition to lifestyle factors and the presence of disease, can be explained to a significant extent by psychological factors, in a similar way for both men and women [5].

Advances within the field of psychoneuroimmunology have led to a detailed knowledge about behavioral-neuralendocrine-immune system interactions [6]. While psychosocial stress and negative emotions are, themselves, predictors for illness and mortality [7], they have also been related to increased levels of inflammatory cytokines, e.g., interleukin (IL)-6 [8, 9]. Interleukin-6 (IL-6) is a pleiotropic cytokine, affecting several biological processes. Besides the induction of C-reactive protein (CRP), an acute-phase protein widely used as a biomarker of inflammation, IL-6 is also linked to the process of inducing "sickness behavior," a term given to the process whereby the cytokines affect sleep, eating behavior, and mood states, making a person experience feelings of "sickness," discomfort, and low energy [10], all suggested to be associated with low self-rated health (SRH) [11].

It has been suggested independently by several groups that there is an association between HRQoL and inflammatory biomarkers. This has been shown for SRH [12-15], but also for more elaborated instruments: Both the SF-36, or other generic HRQoL instruments in the same family, as well as various disease-specific HRQoL instruments have been used in studies where it has been postulated that the relation between HRQoL and mortality includes a psychoneuroimmunological pathway. However, although there is some empirical support for the associations between various HRQoL measures and cytokines, results have been inconsistent and inconclusive [16-26]. Similarly, inconsistent results have also been found regarding the association between HRQoL and CRP [26-30]. This may, at least in part, be explained by the heterogeneity of the patient groups studied, as well as rather small study populations.

As far as we know, there is only one large-scale study using a combination of inflammatory biomarkers when evaluating the association between HRQoL and low-grade inflammation.

A population-based study of the relation between fatigue [measured using the vitality scale (VT) of the SF-36 questionnaire] and a joint elevation of CRP and IL-6 showed a greater risk of a low score of the VT scale, than for elevated levels of CRP or IL-6 separately. The other scales of the SF-36 were not evaluated in this study [31].

In parallel, low-grade inflammation has been found to predict mortality in older people, independently of the presence of disease $[32,33]$. Of note, the combination of elevated levels of both IL-6 and CRP has been found to be associated with a higher mortality risk than measures based on either of the biomarkers alone [33].
The aim of the present study was to evaluate associations between HRQoL and low-grade inflammation in a Swedish general population. In particular, we aimed to investigate a combined measure of CRP and IL-6 in comparison with one biomarker at a time. Our hypothesis was that a combination of CRP and IL-6 would have stronger associations with low HRQoL, than evaluating each biomarker separately.

\section{Methods}

\section{Subjects}

Data were collected between October 2003 and May 2004, using random sampling (stratified according to the catchment areas of 10 different primary health-care centers, sex, and age at 5-year intervals) of the population in the county of Östergötland, Sweden. An invitation letter was sent by post, while signing and returning a reply form provided informed consent. Participants were enrolled until the predetermined sample size of 500 women and 500 men between the ages 45 and 69 was obtained (five 5-year age groups with 50 women and 50 men in each), and finally resulted in 505 women and 502 men. This constituted the basis of the ongoing, prospective Life conditions, Stress, and Health (LSH) study, with a response rate of $62.5 \%$ [34]. The LSH study was designed to investigate whether the relationship between socioeconomic status and coronary heart disease might be mediated through biopsychosocial pathways. Since the primary outcome in this study is coronary heart disease, the age group 45-69 was chosen to optimize the number of outcomes. Exclusion criteria were severe physical or mental disease, or difficulties in understanding the Swedish language. The study sample was representative of the population in terms of educational attainment, immigrant status, and employment rates.

\section{Procedures}

As part of the protocol of the LSH study, participants visited their primary health-care centers, where anthropometric and blood pressure measurements, in addition to blood, urine, and saliva samples, were obtained. All samples were collected in a fasting state. Out of the 1007 participants, blood samples were eligible for analysis from 961 participants.

Patients were instructed to reschedule their appointment if they were currently experiencing any acute infections, e.g., a common cold. At the visit, information about the voluntariness of participating in the study was given verbally. In order to ensure standardization of the data 
collection, nurses collecting data at the 10 primary healthcare centers were trained together.

Except for sex and age, all other measures in the present study were self-reported (from questionnaires).

\section{Measures}

\section{$H R Q o L$}

The Swedish standard version 1 of SF-36 [1, 35] was used to measure HRQoL. Items are aggregated into eight multiitem scales, called Physical Functioning (PF), Role-Physical (RP), Bodily Pain (BP), General Health (GH), Vitality (VT), Social Functioning (SF), Role-Emotional (RE), and Mental Health (MH). Items were transformed and summed according to the manual of the instrument, to give scores from 0 to 100 for each scale, with a higher score indicating a better HRQoL [1, 35].

\section{Biological markers}

Plasma levels (EDTA plasma) of IL-6 were measured with ultrasensitive bead kit technology (Invitrogen Co, Carlsbad, CA, USA) according to the manufacturer's instructions and analyzed on a Luminex ${ }^{\circledR} 100^{\mathrm{TM}}$ system (Austin, TX, USA). The lower limit of detection was $1.68 \mathrm{pg} / \mathrm{ml}$ and inter-assay coefficient of variance (CV) of $7.0 \%$, and proportion of samples with detectable levels was $40 \%$. Samples below the detection levels were given a value that was a third of the detection limit.

C-reactive protein (CRP) was measured in EDTA plasma by a highly sensitive latex-enhanced turbidimetric immunoassay (Roche Diagnostics GmbH, Vienna, Austria) with a lower detection limit of $0.03 \mathrm{mg} / \mathrm{l}$ and $\mathrm{CV}$ of $1.7 \%$. Detectable levels were found for all samples but one, which received a value of zero.

Aliquots of plasma $(0.5 \mathrm{ml})$ were stored in $-70^{\circ}$ Celsius approximately 40 months before analysis.

\section{Presence of disease}

The concept "Presence of disease" included two different variables. The first variable, "Medical conditions," was defined as referring to a participant having at least one of 14 medical conditions. Data in the LSH study on medical conditions were self-reported using a checklist. Participants were asked whether they had ever been diagnosed by a physician with any of the 12 following medical conditions: myocardial infarction, angina pectoris, stroke, chronic obstructive pulmonary disease, cancer, asthma/allergy, dyspepsia/peptic ulcer, kidney disease, celiac disease, hypertension, hyperlipidemia or diabetes mellitus. An open question asking about the presence of other medical conditions than the above concluded the checklist. Rheumatic disease and fibromyalgia were common enough to be added to our variable "Medical conditions." Another aspect of illness important to HRQoL is pain, and the questionnaire contained a question about the presence of musculoskeletal pain in the back of the neck and/or in the back (henceforth referred to only as back pain), constituting the second variable, "Back pain."

\section{Lifestyle factors}

Smoking habits were categorized as being either a smoker (at least one cigarette a day) or not. Those who had quit smoking within the last 5 years due to illness were also included in the smoker category. Hazardous alcohol consumption was defined as drinking $\geq 9 / 14$ (women/men) standard glasses/week (one standard glass $=12 \mathrm{~g}$ of alcohol). Those who had abstained from alcohol due to illness were also included in this category. Questions about alcohol consumption were part of a validated Food Frequency Questionnaire [36]. Physical activity was measured by questions about daily physical activity (four levels) and planned physical exercise (five levels). Responses were then combined into four activity levels: regularly active, occasionally active, seldom active or inactive [37]. For the present study, occasionally and seldom active were then merged into one category. Body mass index (BMI) was used as a measure of weight control and categorized as $<25,25-30$, or $>30$. Weight and height used for calculating BMI were measured by the nurses during visits to the primary health-care centers.

\section{Psychological factors}

The questionnaires in the LSH study included a broad range of instruments measuring psychosocial variables. Earlier [5] we found that, after adjustment for effects of age, sex, presence of disease, and lifestyle, the following two instruments (dimensions) were among those that contributed most strongly to the variation of SF 36 scores, and therefore they were included in the present study. One instrument represents psychological risk factors (risk factors for disease; lower scores being favorable). This is The Center for Epidemiologic Studies Depression scale (CESD) [38], which was developed in the 1970s to capture depressed moods in epidemiological studies. The other instrument measures resources (that supposedly protect against disease; higher scores being favorable). This is Sense of Coherence (SoC), which reflects the extent to which one feels one's own life to be comprehensible, manageable, and meaningful [39]. 


\section{Statistical methods}

Prior to analyses, cutoffs were set at $>10 \mathrm{mg} / \mathrm{l}$ for CRP and $>20 \mathrm{pg} / \mathrm{ml}$ for IL-6, to exclude participants with an acute inflammatory response due to, e.g., ongoing infections ( $n=32$ for CRP, $n=17$ for IL-6).

Descriptive data include mean (SD; range) and frequency.

Partial correlation analyses, adjusted for age and sex, were used to explore the relation between the SF-36 and the biomarkers, and a Fisher $r-z$ transformation was used to investigate differences in correlation coefficients between women and men.

The data set was considered to be large enough to use linear regression analyses on SF-36 scores [40]. Linear regressions (adjusted for age and sex) were used to explore the relation between the SF-36 and the explanatory variables used in the regression analyses, i.e., inflammatory biomarkers presence of disease, lifestyle, and psychological factors. The two biomarkers were evaluated one at a time. The combined effect of CRP and IL-6 was examined by creating a composite variable with four categories: low CRP and low IL-6, high CRP and low IL-6, low CRP and high IL6, and high CRP and high IL-6. Low CRP was defined as CRP $<1 \mathrm{mg} / \mathrm{l}$, and high CRP as $>3 \mathrm{mg} / \mathrm{l}$, using the Centers for Disease Control/American Heart Association (CDC/AHA) criteria regarding risk assessments for cardiovascular disease [40]. To define high IL-6 levels in the present study, we used the same proportion of study participants as found for the high category of CRP. This corresponds to an IL-6 level of $3.25 \mathrm{pg} / \mathrm{ml}$. As the levels to define high and low levels of the biomarkers are arbitrary, four altered definitions were used to categorize an elevation of the biomarkers, using (a) highest quartile (CRP $>2.26 \mathrm{mg} / \mathrm{l}$ and IL-6 $>2.58 \mathrm{pg} / \mathrm{ml}$ ), (b) median split (CRP > $0.85 \mathrm{mg} / \mathrm{l}$ and IL-6 $>0.56 \mathrm{pg} / \mathrm{ml}$ ), (c) the same absolute cutoffs as used in the article by Cho et al. $(\mathrm{CRP}>1.0 \mathrm{mg} / \mathrm{l}$ and IL-6 $>1.5 \mathrm{pg} / \mathrm{ml})$ [31], and (d) the same absolute cutoffs as used in the article by Harris et al. [33] $(\mathrm{CRP}>2.78 \mathrm{mg} / \mathrm{l}$ and IL-6 $>3.15 \mathrm{pg} / \mathrm{ml})$.

A two-sided probability value of $p \leq 0.05$ was considered as statistically significant. Analyses were performed in STATA statistical software, release 11.0 (Stata Corporation, College Station, TX, USA), IBM SPSS for Windows statistical software, release 21 (IBM Corporation, Armonk, NY, USA).

\section{Results}

Descriptive data regarding the study sample $(n=905)$ are given in Table 1. Significant sex differences were seen for many of the variables in Table 1 (back pain, BMI, alcohol
Table 1 Characteristics of the study population $(n=905)$

\begin{tabular}{|c|c|c|c|}
\hline & & $\%$ & $n$ \\
\hline \multicolumn{4}{|l|}{ Sex } \\
\hline \multicolumn{2}{|l|}{ Women } & 50 & 454 \\
\hline \multicolumn{4}{|l|}{ Age } \\
\hline \multicolumn{2}{|l|}{$45-49$} & 20 & 179 \\
\hline \multicolumn{2}{|l|}{$50-54$} & 21 & 188 \\
\hline \multicolumn{2}{|l|}{$55-59$} & 20 & 185 \\
\hline \multicolumn{2}{|l|}{$60-64$} & 20 & 178 \\
\hline \multicolumn{2}{|l|}{$65-69$} & 19 & 175 \\
\hline \multicolumn{4}{|l|}{ Medical conditions } \\
\hline \multicolumn{2}{|l|}{ One or more of all diseases } & 55 & 497 \\
\hline \multicolumn{4}{|l|}{ Back pain } \\
\hline \multicolumn{2}{|l|}{ Yes } & 41 & 375 \\
\hline \multicolumn{4}{|l|}{ Smoking } \\
\hline \multicolumn{2}{|l|}{ Yes } & 21 & 193 \\
\hline \multicolumn{4}{|l|}{ Alcohol consumption } \\
\hline \multicolumn{2}{|l|}{9 (women)/14 (men) or more glasses/week } & 10 & 86 \\
\hline \multicolumn{4}{|l|}{ Body mass index } \\
\hline \multicolumn{2}{|l|}{$<25$} & 38 & 340 \\
\hline \multicolumn{2}{|l|}{$25-30$} & 43 & 385 \\
\hline \multicolumn{2}{|l|}{$>30$} & 19 & 171 \\
\hline \multicolumn{4}{|l|}{ Physical activity } \\
\hline \multicolumn{2}{|l|}{ Inactive } & 4 & 36 \\
\hline \multicolumn{2}{|l|}{ Occasionally/seldom active } & 76 & 640 \\
\hline \multirow[t]{2}{*}{ Regularly active } & & 19 & 163 \\
\hline & Mean & SD & Range \\
\hline \multicolumn{4}{|l|}{ Psychological instruments } \\
\hline \multicolumn{4}{|l|}{$\begin{array}{l}\text { Studies Depression scale (possible } \\
\text { range } 0-60 \text { ) }\end{array}$} \\
\hline \multicolumn{4}{|l|}{$\begin{array}{l}\text { SUC, Sense of Coherence (possible } \\
\text { range 13-91) }\end{array}$} \\
\hline SF-36 & & & \\
\hline $\begin{array}{l}\text { PF, Physical Functioning (possible range } \\
0-100 \text { ) }\end{array}$ & 84.7 & 18 & $0-100$ \\
\hline $\begin{array}{l}\text { RP, Role-Physical (possible range } \\
\text { 0-100) }\end{array}$ & 81.6 & 34 & $0-100$ \\
\hline BP, Bodily Pain (possible range 0-100) & 69.2 & 26 & $0-100$ \\
\hline $\begin{array}{l}\text { GH, General Health (possible range } \\
0-100 \text { ) }\end{array}$ & 70.5 & 21 & $5-100$ \\
\hline VT, Vitality (possible range 0-100) & 66.6 & 23 & $0-100$ \\
\hline $\begin{array}{l}\text { SF, Social Functioning (possible range } \\
0-100 \text { ) }\end{array}$ & 87.8 & 20 & $0-100$ \\
\hline $\begin{array}{l}\text { RE, Role-Emotional (possible range } \\
\text { 0-100) }\end{array}$ & 86.2 & 29 & $0-100$ \\
\hline $\begin{array}{l}\text { MH, Mental Health (possible range } \\
0-100 \text { ) }\end{array}$ & 79.3 & 17 & $8-100$ \\
\hline Biomarkers & & & \\
\hline IL-6 (pg/ml) & 1.9 & 2.5 & $0.56-19.5$ \\
\hline CRP (mg/l) & 1.7 & 2.0 & $0-9.9$ \\
\hline
\end{tabular}


Table 1 continued

\begin{tabular}{lcc}
\hline & $\%$ & $n$ \\
\hline Combinations of CRP and IL-6 $(n=534)$ & & \\
Low CRP low IL-6 (CRP $<1 \mathrm{mg} / \mathrm{l}, \mathrm{IL}-6<0.57 \mathrm{pg} / \mathrm{ml})$ & 67 & 355 \\
High CRP low IL-6 (CRP $>3 \mathrm{mg} / \mathrm{l}, \mathrm{IL}-6<0.57 \mathrm{pg} / \mathrm{ml})$ & 12 & 66 \\
Low CRP high IL-6 (CRP $<1 \mathrm{mg} / \mathrm{l}, \mathrm{IL}-6>3.25 \mathrm{pg} / \mathrm{ml})$ & 10 & 52 \\
High CRP high IL-6 (CRP $>3 \mathrm{mg} / \mathrm{l}, \mathrm{IL}-6>3.25 \mathrm{pg} / \mathrm{ml})$ & 11 & 61 \\
\hline
\end{tabular}

consumption, CRP, and all scales of the SF-36 except the RE scale). Therefore, correlation analyses between the SF36 and the biomarkers were first carried out separately for women and men. However, the Fischer $r-z$ transformation did not show any significant differences in the correlation coefficients for women and men, and separating the analyses by sex did not change the main findings. Hence, further analyses were adjusted for sex, but were not performed separately for women and men.

The results of partial correlations (adjusted for age and sex) between the scales of the SF-36 and the biomarkers are shown in Table 2. Significant correlation coefficients for every scale of the SF-36 were found for IL-6, whereas CRP showed significant relations for all scales except the MH scale.

All lifestyle and psychological factors, as well as presence of disease, were related to HRQoL, as expected (Table 3). High alcohol consumption had the lowest coefficients in regard to SF-36, but still significant to five of the eight scales.

In Table 4, the combined measure of CRP and IL-6 in relation to SF-36 scale scores is shown. When running dummy variables of the combined variable adjusted for age and sex, the group with both elevated CRP and elevated IL6 has significantly lower SF-score for all the subscales than any other group. After full adjustments, scale scores are

Table 2 Partial correlation between the SF-36 and the inflammatory biomarkers, adjusted for age and sex

\begin{tabular}{|c|c|c|c|c|}
\hline \multirow[t]{2}{*}{ SF-36 } & \multicolumn{2}{|l|}{ IL-6 } & \multicolumn{2}{|l|}{ CRP } \\
\hline & $r$ & $p$ & $r$ & $p$ \\
\hline PF, Physical Functioning & -0.18 & $<\mathbf{0 . 0 0 1}$ & -0.15 & $<\mathbf{0 . 0 0 1}$ \\
\hline RP, Role-Physical & -0.09 & 0.005 & -0.12 & $<\mathbf{0 . 0 0 1}$ \\
\hline BP, Bodily Pain & $-\mathbf{0 . 1 0}$ & 0.001 & -0.12 & $<\mathbf{0 . 0 0 1}$ \\
\hline GH, General Health & -0.15 & $<\mathbf{0 . 0 0 1}$ & -0.12 & $<\mathbf{0 . 0 0 1}$ \\
\hline VT, Vitality & $-\mathbf{0 . 1 0}$ & 0.001 & -0.07 & 0.023 \\
\hline SF, Social Functioning & -0.13 & $<\mathbf{0 . 0 0 1}$ & -0.09 & 0.005 \\
\hline RE, Role-Emotional & $-\mathbf{0 . 1 3}$ & $<\mathbf{0 . 0 0 1}$ & -0.08 & 0.009 \\
\hline MH, Mental Health & -0.12 & $<\mathbf{0 . 0 0 1}$ & -0.02 & 0.393 \\
\hline
\end{tabular}

Statistically significant correlations are shown in bold. $n=855-905$ consistently significantly lower in 19 out of 24 comparisons for the group with both elevated CRP and IL-6. In Fig. 1, the mean scores are shown for each group, along with agestandardized norm values [41]. The groups with either no elevation or with elevation of one of the biomarkers have adjusted mean values that are higher or in the same range as the norm values, whereas the group with both elevated CRP and elevated IL-6 is considerably lower.

The smallest differences were seen for the Mental Health scale (where only one of the three comparisons was significant), and the most pronounced difference was found for physical role, where the difference in scale scores to the other groups was about -17 to -18 scale steps.

Four altered ways to define high vs low levels were used to out-rule potential spurious findings due to arbitrary cutoffs. Results were largely unchanged for two of them, namely using either the highest quartile (CRP $>2.26 \mathrm{mg} / \mathrm{l}$ and IL-6 $>2.58 \mathrm{pg} / \mathrm{ml}$ ) or the same absolute cutoffs as used in the article by Harris et al. [33] (CRP $>2.78 \mathrm{mg} / \mathrm{l}$ and IL- $6>3.15 \mathrm{pg} / \mathrm{ml}$ ). These two approaches for altered cutoffs had significantly lower SF-36 scores in the group with elevated levels in both biomarkers, with bodily pain as only exception (data not shown).

However, for median split (CRP $>0.85 \mathrm{mg} / \mathrm{l}$ and IL$6>0.56 \mathrm{pg} / \mathrm{ml}$ ) and the same absolute cutoffs as used in the article by Cho et al. [31] (CRP $>1.0 \mathrm{mg} / \mathrm{l}$ and IL$6>1.5 \mathrm{pg} / \mathrm{ml}$ ), there were significant differences only for social function and emotional role function, with nonsignificant differences in the other comparisons (data not shown).

Adjusting for physical activity and BMI either as ordinal categories or dummy variables had no major impact on any of the above regressions.

\section{Discussion}

In the present study, we found significant negative correlations (after adjustment for age and sex) for all scales of the SF-36 to plasma levels of IL-6 and CRP (except the MH scale for CRP). The combined measure of both elevated CRP and IL-6 was associated with markedly lower SF-scores than the groups with elevation of either one of them. The significantly lower SF-scores for the group with subclinical elevations of both CRP and IL-6 remained after adjustments for medical conditions, lifestyle factors, and psychological factors.

Our findings corroborate the few earlier populationbased studies using a combined measure of inflammatory biomarkers rather than looking at biomarkers one by one.

Harris et al. [33] found that in a population of older nondisabled persons (age $77 \pm 3.2$ years), there was a 2.6 times greater mortality for the joint elevation of high but 
Table 3 SF-36 in relation to potential explanatory variables

\begin{tabular}{|c|c|c|c|c|c|c|c|c|c|}
\hline \multirow[t]{2}{*}{ Explanatory factors } & & \multicolumn{8}{|l|}{ SF-36 } \\
\hline & & $\mathrm{PF}$ & $\mathrm{RP}$ & BP & GH & VT & SF & $\mathrm{RE}$ & MH \\
\hline \multirow[t]{2}{*}{ Medical conditions $(\mathrm{y} / n)$} & & -6.5 & -12.5 & -8.8 & -11.1 & -8.7 & -6.2 & -5.4 & -3.6 \\
\hline & $p$ & $<\mathbf{0 . 0 0 1}$ & $<\mathbf{0 . 0 0 1}$ & $<\mathbf{0 . 0 0 1}$ & $<0.001$ & $<\mathbf{0 . 0 0 1}$ & $<\mathbf{0 . 0 0 1}$ & 0.008 & 0.002 \\
\hline \multirow[t]{2}{*}{ Back pain $(y / n)$} & & -10.7 & -17.8 & -27.1 & -14.4 & -14.7 & -7.1 & -6.9 & -5.4 \\
\hline & $p$ & 0.001 & 0.001 & 0.001 & 0.001 & 0.001 & 0.001 & 0.001 & 0.001 \\
\hline \multirow[t]{2}{*}{ Smoking $(\mathrm{y} / n)$} & & -7.3 & -8.8 & -8.2 & -6.3 & -7.2 & -5.8 & -9.3 & -6.1 \\
\hline & $p$ & 0.001 & 0.001 & 0.001 & 0.001 & 0.001 & 0.001 & 0.001 & 0.001 \\
\hline \multirow[t]{2}{*}{ High alcohol consumption $(\mathrm{y} / n)$} & & -5.4 & -9.5 & -3.1 & -5.1 & -4.6 & -6.9 & -11.2 & -3.6 \\
\hline & $p$ & 0.008 & 0.015 & 0.304 & 0.035 & 0.076 & 0.002 & 0.001 & 0.069 \\
\hline \multirow[t]{2}{*}{ BMI (three categories) } & & -5.8 & -7.0 & -5.4 & -5.8 & -4.3 & $-\mathbf{3 . 0}$ & -3.2 & -1.1 \\
\hline & $p$ & 0.001 & 0.001 & 0.001 & 0.001 & 0.001 & 0.001 & $\mathbf{0 . 0 2 0}$ & 0.144 \\
\hline \multirow[t]{2}{*}{ Physical activity (three categories) } & & 11.2 & 9.7 & 7.6 & 10.0 & 8.8 & 4.2 & 4.8 & 2.6 \\
\hline & $p$ & 0.001 & 0.001 & 0.001 & 0.001 & 0.001 & 0.002 & $\mathbf{0 . 0 3 2}$ & 0.042 \\
\hline \multirow[t]{2}{*}{ Sense of coherence } & & 3.5 & 7.7 & 4.6 & 8.2 & 9.5 & 6.8 & 10.9 & 8.9 \\
\hline & $p$ & 0.001 & 0.001 & 0.001 & 0.001 & 0.001 & 0.001 & 0.001 & 0.001 \\
\hline \multirow[t]{2}{*}{ CES-D } & & -4.7 & -10.9 & -6.3 & -10.0 & -13.2 & -10.5 & -16.5 & -12.4 \\
\hline & $p$ & 0.001 & 0.001 & 0.001 & 0.001 & 0.001 & 0.001 & 0.001 & 0.001 \\
\hline
\end{tabular}

Regressions adjusted for age and sex. Beta coefficients expressed as change per category (dichotomy, or three categories for body mass index and physical activity) or per SD increment in continuous scales (psychological factors). Statistically significant findings are shown in bold. $n=878-976$

SF-36: $P F$ Physical Functioning, $R P$ Role-Physical, $B P$ Bodily Pain, $G H$ General Health, VT Vitality, SF Social Functioning, $R E$ RoleEmotional, $M H$ Mental Health, $C E S-D$ Center for Epidemiologic Studies Depression scale

Table 4 SF-36 for different combinations of CRP and IL-6

\begin{tabular}{|c|c|c|c|c|c|c|c|c|c|}
\hline \multirow[t]{2}{*}{ SF-36 } & & \multicolumn{2}{|c|}{ High CRP low IL-6 $(n=66)$} & \multicolumn{2}{|c|}{ Low CRP high IL-6 $(n=61)$} & \multicolumn{2}{|c|}{ Low CRP low IL-6 $(n=355)$} & \multicolumn{2}{|l|}{$R^{2}$ values } \\
\hline & & Model a & Model b & Model a & Model b & Model a & Model b & Model a & Model b \\
\hline \multirow[t]{2}{*}{ PF } & & 10.7 & 9.8 & 10.7 & 8.1 & 14.7 & 9.7 & 0.12 & 0.33 \\
\hline & $p$ & $<\mathbf{0 . 0 0 1}$ & $<0.001$ & $<\mathbf{0 . 0 0 1}$ & 0.005 & $<0.001$ & $<0.001$ & & \\
\hline \multirow[t]{2}{*}{ RP } & & 14.8 & 17.1 & 20.7 & 18.1 & 20.0 & 17.1 & 0.04 & 0.20 \\
\hline & $p$ & 0.015 & 0.006 & 0.001 & 0.004 & $<0.001$ & 0.001 & & \\
\hline \multirow[t]{2}{*}{ BP } & & 10.3 & 5.4 & 16.2 & 8.8 & 17.0 & 7.9 & 0.06 & 0.38 \\
\hline & $p$ & $\mathbf{0 . 0 3 0}$ & 0.200 & 0.001 & 0.040 & $<0.001$ & 0.028 & & \\
\hline \multirow[t]{2}{*}{ GH } & & 12.1 & 11.0 & 15.1 & 9.4 & 16.1 & 9.7 & 0.07 & 0.38 \\
\hline & $p$ & 0.002 & 0.002 & $<0.001$ & 0.008 & $<0.001$ & 0.001 & & \\
\hline \multirow[t]{2}{*}{ VT } & & 9.1 & 11.3 & 12.6 & 9.9 & 11.0 & 6.1 & 0.09 & 0.47 \\
\hline & $p$ & 0.026 & 0.001 & 0.002 & 0.005 & 0.001 & 0.035 & & \\
\hline \multirow[t]{2}{*}{ SF } & & 8.0 & 8.1 & 8.5 & 4.2 & 11.9 & 7.0 & 0.07 & 0.35 \\
\hline & $p$ & 0.024 & 0.013 & 0.018 & 0.206 & $<0.001$ & 0.010 & & \\
\hline \multirow[t]{2}{*}{ RE } & & 13.9 & 16.7 & 11.3 & 8.0 & 15.4 & 11.2 & 0.03 & 0.26 \\
\hline & $p$ & 0.011 & 0.002 & 0.040 & 0.145 & 0.001 & 0.014 & & \\
\hline \multirow[t]{2}{*}{ MH } & & 8.8 & 8.9 & 7.1 & 3.9 & 8.1 & 4.2 & 0.07 & 0.49 \\
\hline & $p$ & 0.007 & 0.001 & 0.031 & 0.152 & 0.002 & 0.062 & & \\
\hline
\end{tabular}

Beta coefficients represent differences in SF-36 score for dummy variables in comparison with the group with high CRP and high IL-6 ( $n=52$ ). Model a adjusted for age and sex. Model b adjusted for age, sex, presence of disease, lifestyle factors, and psychological factors. Statistically significant findings are shown in bold

$\mathrm{R} 2$, coefficient of determination, is shown for model $\mathrm{a}$ and $\mathrm{b}$ for each of the scales in SF-36 are in bold italic 


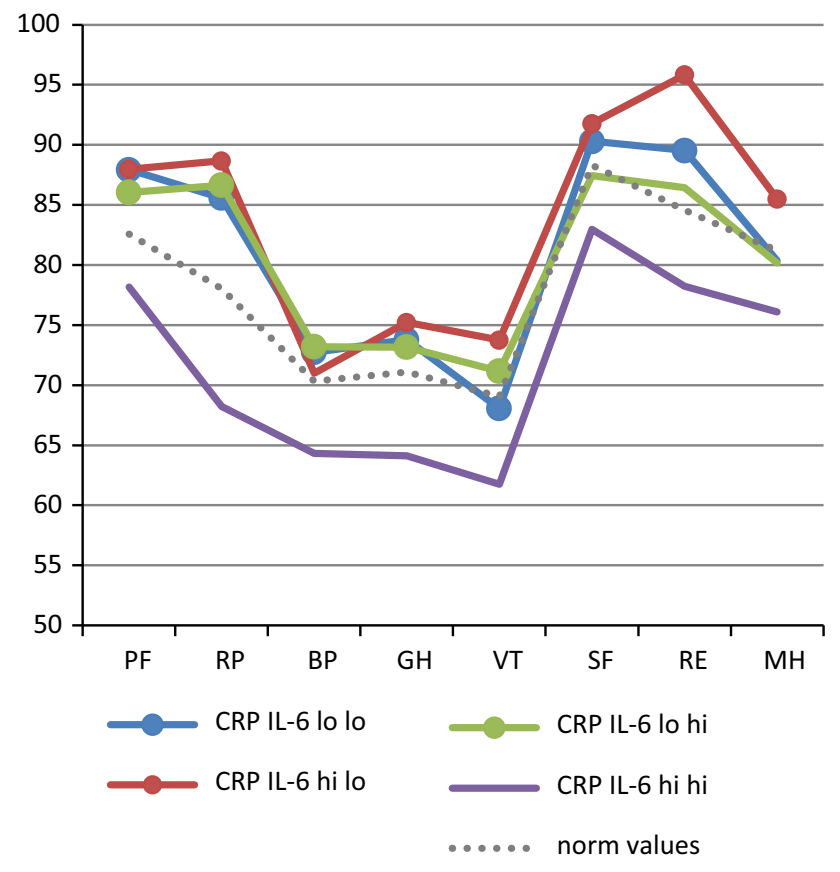

Fig. 1 Mean SF-36 scale scores for different combinations of CRP and IL-6, adjusted for age, sex, presence of disease, lifestyle factors, and psychological factors. $n=435-457$. SF-36: $P F$ Physical Functioning, $R P$ Role-Physical, $B P$ Bodily Pain, $G H$ General Health, $V T$ Vitality, $S F$ Social Functioning, $R E$ Role-Emotional, $M H$ Mental Health. $C R P$ C-reactive protein, $I L$ interleukin. CRP hi $=3-10 \mathrm{mg} / \mathrm{l}$, CRP lo $\leq 1 \mathrm{mg} / \mathrm{l}$, IL-6 hi $=3.25-20 \mathrm{pg} / \mathrm{ml}$, IL-6 lo $\leq 0.56 \mathrm{pg} / \mathrm{ml}$. Dashed line represents Swedish norm values standardized to the gender and age distribution in the study population. Significant differences in group comparisons in relation to group with elevated levels of both CRP and IL-6 are marked with a filled circle. The group with elevated levels of both CRP and IL-6 has significantly lower mean levels of SF-36 scores than other groups in 19 out of 24 comparisons (all except BP for CRP IL6 hi lo, SF, RE and MH for CRP IL6 lo hi, and MH for CRP IL-6 lo lo)

subclinical CRP ((fourth quartile, $\geq 2.78 \mathrm{mg} / \mathrm{l}$ ) and IL-6 (fourth quartile, $>3.19 \mathrm{pg} / \mathrm{ml}$ ) than for lower than median values $(<1.57 \mathrm{mg} / \mathrm{l}$ and $2.08 \mathrm{pg} / \mathrm{ml}$, respectively). Persons with only high IL-6 also had a higher mortality risk, while persons with only high CRP did not.

In the Whitehall II study, Cho et al. [31] primarily used the same approach as we did to find cutoffs for CRP, namely the CDC/AHA criteria [41]. However, when categorizing the joint elevation, they used the cutoffs high $\mathrm{CRP} \geq 1 \mathrm{mg} / \mathrm{l}$ and high IL- $6 \geq 1.5 \mathrm{pg} / \mathrm{ml}$. Fatigue was defined as scoring $\leq 50$ on the VT scale of the SF-36 (28\% of the study population). Of the respondents with no fatigue at baseline, $20 \%$ scored $\leq 50$ at follow-up. Persons with both high CRP and high IL-6 had significantly higher risk of developing fatigue than persons with only low values, while those with only one elevated biomarker did not. Thus, similar to our study, the joint elevation of CRP and IL-6 had a stronger association with VT than was the case for elevation in just one of the biomarkers.
Both Harris et al. [33] and Cho et al. [31] used wellcharacterized study populations, allowing them to adjust for a number of relevant factors, similar to our approach. In all three studies, the relations remained after the adjustments, implying that there seems to be a biological link between low-grade inflammation and HRQoL. In particular, although the studies use in part different methods and biomarker levels, both Harris et al. [33] and Cho et al. [31] indicate that neither CRP nor IL-6 alone is a sufficient measure and that a combined measure of the two is superior. Our data confirm that subclinical elevation in only one of these two biomarkers may be cumbersome to evaluate as there are small differences in comparison with the group without any elevation, whereas an elevation in both may be a better marker for sustained elevations in low-grade inflammation.

There were no major differences between the cutoffs used based on proportion corresponding to CRP $>3 \mathrm{mg} / \mathrm{l}$, highest quartile or categorization used by Harris [33]. This is to be expected, as all these three arbitrary cutoffs are close to one another in terms of absolute comparisons. In contrast, our findings were altered substantially when using median split or the categorization used by Cho [31]. This is also to be expected, as both these categorizations include a high number of participants as "high" although inflammation is relatively low (starting from CRP $>1 \mathrm{mg} / \mathrm{l}$ ). We propose that the proportion having $3 \mathrm{mg} / \mathrm{l}$ or higher for CRP could be used to set the cutoff for IL-6. An absolute level of IL-6 may be cumbersome to define, due to difficulties in measurements of low concentrations and variations across methodology used.

It might be argued that the large effect of combining the two biomarkers is unexpected, since IL- 6 is one of the main inducers to release CRP. Therefore, elevations of CRP reflect elevations of IL-6 to a substantial extent, and the correlation between the two should be high. However, importantly, the kinetics differ between the two biomarkers, both in release patterns as well as concentrations in circulation, where both fluctuates considerably but IL-6 has a much lower half-life than CRP. In samples from a normal population, we might speculate that elevations in one of the two biomarkers to a large extent reflect functional acutephase response among certain individuals, whereas elevations in both may be a more valid measure for a longstanding subclinical inflammation. Thus, it would be expected that a combination of the two biomarkers has an impact on the association with HRQoL, whereas a rise in just one of them does not.

A potential limitation of the study was that the proportion of samples with detectable plasma levels for IL-6 was low, which might negatively influence the correlation and regression analyses. However, IL-6 still showed consistent and highly significant correlations to SF-36. Unarguably, 
difficulties with the measurement bring limitations to explore appropriate cutoff levels for IL-6. However, this limitation does not have an impact on our major finding, that the combination of the two biomarkers has a stronger association with HRQoL, than the elevation of either one of them.

\section{Conclusion}

This study demonstrates that there is a relationship between HRQoL and low-grade inflammation. In particular, the association is significantly stronger when using a combined measure of IL-6 and CRP in comparison with elevation of either one of them.

\section{Compliance with ethical standards}

Conflict of interest All authors declare that there are no conflicts of interest.

Ethical standard The LSH study was funded by the Swedish Research Council (2004-1881) and the Swedish Heart and Lung Foundation (2004053). The study design was approved by the regional Ethical Review Board, Linköping, Sweden (02-0324), and informed consent was obtained from all individual participants included in the study. All procedures performed were in accordance with the ethical standards of the Swedish Research Council and with the 1964 Helsinki Declaration and its later amendments.

Open Access This article is distributed under the terms of the Creative Commons Attribution 4.0 International License (http://crea tivecommons.org/licenses/by/4.0/), which permits unrestricted use, distribution, and reproduction in any medium, provided you give appropriate credit to the original author(s) and the source, provide a link to the Creative Commons license, and indicate if changes were made.

\section{References}

1. Ware, J. E. Jr., \& Sherbourne, C. D. (1992). The MOS 36-item short-form health survey (SF-36). I. Conceptual framework and item selection. Medical Care, 30(6), 473-483.

2. Otero-Rodriguez, A., Leon-Munoz, L. M., Balboa-Castillo, T., Banegas, J. R., Rodriguez-Artalejo, F., \& Guallar-Castillon, P. (2010). Change in health-related quality of life as a predictor of mortality in the older adults. Quality of Life Research, 19(1), 15-23.

3. Sadetsky, N., Hubbard, A., Carroll, P. R., \& Satariano, W. (2009). Predictive value of serial measurements of quality of life on allcause mortality in prostate cancer patients: Data from CaPSURE (cancer of the prostate strategic urologic research endeavor) database. Quality of Life Research, 18(8), 1019-1027.

4. Tsai, S. Y., Chi, L. Y., Lee, C. H., \& Chou, P. (2007). Healthrelated quality of life as a predictor of mortality among community-dwelling older persons. European Journal of Epidemiology, 22(1), 19-26.

5. Nilsson, E., \& Kristenson, M. (2010). Psychological factors related to physical, social, and mental dimensions of the SF-36: A population-based study of middle-aged women and men. Patient Related Outcome Measures, 1, 153-162.
6. Irwin, M. R. (2008). Human psychoneuroimmunology: 20 years of discovery. Brain, Behavior, and Immunity, 22(2), 129-139.

7. Everson-Rose, S. A., \& Lewis, T. T. (2005). Psychosocial factors and cardiovascular diseases. Annual Review of Public Health, 26, 469-500.

8. Steptoe, A., Hamer, M., \& Chida, Y. (2007). The effects of acute psychological stress on circulating inflammatory factors in humans: A review and meta-analysis. Brain, Behavior, and Immunity, 21(7), 901-912.

9. Sjogren, E., Leanderson, P., Kristenson, M., \& Ernerudh, J. (2006). Interleukin-6 levels in relation to psychosocial factors: Studies on serum, saliva, and in vitro production by blood mononuclear cells. Brain, Behavior, and Immunity, 20(3), 270-278.

10. Dantzer, R., \& Kelley, K. W. (2007). Twenty years of research on cytokine-induced sickness behavior. Brain, Behavior, and Immunity, 21(2), 153-160.

11. Rabin, B. S. (1999). Stress, immune function, and health: The connection. New York, NY: Wiley-Liss.

12. Christian, L. M., Glaser, R., Porter, K., Malarkey, W. B., Beversdorf, D., \& Kiecolt-Glaser, J. K. (2011). Poorer self-rated health is associated with elevated inflammatory markers among older adults. Psychoneuroendocrinology, 36(10), 1495-1504.

13. Cohen, H. J., Pieper, C. F., Harris, T., Rao, K. M., \& Currie, M. S. (1997). The association of plasma IL-6 levels with functional disability in community-dwelling elderly. Journals of Gerontology. Series A, Biological Sciences and Medical Sciences, 52(4), M201-M208.

14. Lekander, M., Elofsson, S., Neve, I. M., Hansson, L. O., \& Unden, A. L. (2004). Self-rated health is related to levels of circulating cytokines. Psychosomatic Medicine, 66(4), 559-563.

15. Janszky, I., Lekander, M., Blom, M., Georgiades, A., \& Ahnve, S. (2005). Self-rated health and vital exhaustion, but not depression, is related to inflammation in women with coronary heart disease. Brain, Behavior, and Immunity, 19(6), 555-563.

16. Baturone, R., Soto, M. J., Marquez, M., Macias, I., de Oca, M. M., Medina, F., et al. (2009). Health-related quality of life in patients with primary Sjogren's syndrome: Relationship with serum levels of proinflammatory cytokines. Scandinavian Journal of Rheumatology, 38(5), 386-389.

17. Costanzo, E. S., Lutgendorf, S. K., Sood, A. K., Anderson, B., Sorosky, J., \& Lubaroff, D. M. (2005). Psychosocial factors and interleukin-6 among women with advanced ovarian cancer. Cancer, 104(2), 305-313.

18. Falasca, K., Mancino, P., Ucciferri, C., Dalessandro, M., Manzoli, L., Pizzigallo, E., et al. (2009). Quality of life, depression, and cytokine patterns in patients with chronic hepatitis $\mathrm{C}$ treated with antiviral therapy. Clinical and Investigative Medicine, 32(3), E212-E218.

19. Knobel, H., Loge, J. H., Nordoy, T., Kolstad, A. L., Espevik, T., Kvaloy, S., \& Kaasa, S. (2000). High level of fatigue in lymphoma patients treated with high dose therapy. Journal of Pain and Symptom Management, 19(6), 446-456.

20. Matsunaga, M., Isowa, T., Murakami, H., Kasugai, K., Yoneda, M., Kaneko, H., \& Ohira, H. (2009). Association of polymorphism in the human $\mu$-opioid receptor OPRM1 gene with proinflammatory cytokine levels and health perception. Brain, Behavior, and Immunity, 23(7), 931-935.

21. Miller, L. J., Fischer, K. A., Goralnick, S. J., Litt, M., Burleson, J. A., Albertsen, P., \& Kreutzer, D. L. (2002). Nerve growth factor and chronic prostatitis/chronic pelvic pain syndrome. Urology, 59(4), 603-608.

22. Miller, L. J., Fischer, K. A., Goralnick, S. J., Litt, M., Burleson, J. A., Albertsen, P., \& Kreutzer, D. L. (2002). Interleukin-10 levels in seminal plasma: Implications for chronic prostatitis-chronic pelvic pain syndrome. Journal of Urology, 167(2 Pt 1), 753-756.

23. Mommersteeg, P. M., Kupper, N., Schoormans, D., Emons, W., $\&$ Pedersen, S. S. (2010). Health-related quality of life is related 
to cytokine levels at 12 months in patients with chronic heart failure. Brain, Behavior, and Immunity, 24(4), 615-622.

24. Rich, T., Innominato, P. F., Boerner, J., Mormont, M. C., Iacobelli, S., Baron, B., et al. (2005). Elevated serum cytokines correlated with altered behavior, serum cortisol rhythm, and dampened 24-hour rest-activity patterns in patients with metastatic colorectal cancer. Clinical Cancer Research, 11(5), $1757-1764$

25. Shyong, E. Q., Lucchinetti, E., Tagliente, T. M., Hossain, S., Silverstein, J. H., \& Zaugg, M. (2003). Interleukin balance and early recovery from anesthesia in elderly surgical patients exposed to beta-adrenergic antagonism. Journal of Clinical Anesthesia, 15(3), 170-178.

26. Spruit, M. A., Gosselink, R., Troosters, T., Kasran, A., Van Vliet, M., \& Decramer, M. (2005). Low-grade systemic inflammation and the response to exercise training in patients with advanced COPD. Chest, 128(5), 3183-3190.

27. Cummings, D. M., King, D. E., \& Mainous, A. G, 3rd. (2003). C-reactive protein, antiinflammatory drugs, and quality of life in diabetes. Annals of Pharmacotherapy, 37(11), 1593-1597.

28. Dagfinrud, H., Vollestad, N. K., Loge, J. H., Kvien, T. K., \& Mengshoel, A. M. (2005). Fatigue in patients with ankylosing spondylitis: A comparison with the general population and associations with clinical and self-reported measures. Arthritis and Rheumatism, 53(1), 5-11.

29. Kalender, B., Ozdemir, A. C., Dervisoglu, E., \& Ozdemir, O. (2007). Quality of life in chronic kidney disease: Effects of treatment modality, depression, malnutrition and inflammation. International Journal of Clinical Practice, 61(4), 569-576.

30. Ribu, L., Hanestad, B. R., Moum, T., Birkeland, K., \& Rustoen, T. (2007). Health-related quality of life among patients with diabetes and foot ulcers: Association with demographic and clinical characteristics. Journal of Diabetes and Its Complications, 21(4), 227-236.

31. Cho, H. J., Kivimaki, M., Bower, J. E., \& Irwin, M. R. (2013). Association of C-reactive protein and interleukin-6 with newonset fatigue in the Whitehall II prospective cohort study. Psychological Medicine, 43(8), 1773-1783.

32. Wikby, A., Nilsson, B. O., Forsey, R., Thompson, J., Strindhall, J., Lofgren, S., et al. (2006). The immune risk phenotype is associated with IL-6 in the terminal decline stage: Findings from the Swedish NONA immune longitudinal study of very late life functioning. Mechanisms of Ageing and Development, 127(8), 695-704.

33. Harris, T. B., Ferrucci, L., Tracy, R. P., Corti, M. C., Wacholder, S., Ettinger, W. H, Jr, et al. (1999). Associations of elevated interleukin-6 and C-reactive protein levels with mortality in the elderly. The American Journal of Medicine, 106(5), 506-512.

34. Hollman, G., \& Kristenson, M. (2008). The prevalence of the metabolic syndrome and its risk factors in a middle-aged Swedish population-Mainly a function of overweight? European Journal of Cardiovascular Nursing, 7(1), 21-26.

35. Sullivan, M., Karlsson, J., \& Ware, J. E, Jr. (1995). The Swedish SF36 Health Survey - I. Evaluation of data quality, scaling assumptions, reliability and construct validity across general populations in Sweden. Social Science and Medicine, 41(10), 1349-1358.

36. Khani, B. R., Ye, W., Terry, P., \& Wolk, A. (2004). Reproducibility and validity of major dietary patterns among Swedish women assessed with a food-frequency questionnaire. Journal of Nutrition, 134(6), 1541-1545.

37. Kallings, L. V., Leijon, M., Hellenius, M. L., \& Stahle, A. (2008). Physical activity on prescription in primary health care: A followup of physical activity level and quality of life. Scandinavian Journal of Medicine and Science in Sports, 18(2), 154-161.

38. Radloff, L. (1977). The CES-D scale. A self-report depression scale for research in the general population. Applied Psychological Measures, 1(3), 385-401.

39. Antonovsky, A. (1987). Unraveling the mystery of health: How people manage stress and stay well (1st ed.). San Francisco: Jossey-Bass.

40. Walters, S. J., \& Campbell, M. J. (2004). The use of bootstrap methods for analysing health-related quality of life outcomes (particularly the SF-36). Health and Quality of Life Outcomes, 2, 70.

41. Pearson, T. A., Mensah, G. A., Alexander, R. W., Anderson, J. L., Cannon, R. O, 3rd, Criqui, M., et al. (2003). Markers of inflammation and cardiovascular disease: Application to clinical and public health practice: A statement for healthcare professionals from the Centers for Disease Control and Prevention and the American Heart Association. Circulation, 107(3), 499-511. 